\title{
Carbon Emission Estimation \& Reduction in Indian Telecom Operations: A Standardization \& Policy Perspective
}

\author{
Krishna Sirohi \\ President - Impact Innovations in Technology \& Business (i2TB), India; \\ e-mail: president@i2tb.in
}

Received July 2013; Accepted August 2013

\begin{abstract}
This Paper is Standardization Perspective of the problem definition of Carbon Emission Estimation and Reduction exercise in Indian Telecom Networks. It includes the relevant interpretation of the TRAI recommendations, current practices of estimating Carbon emission and the associated issues. It brings out the techno-managerial perspective to estimate carbon emission in Indian Telecom network, description of with the currently adopted methods and their implications. It also suggests how the entire telecom sector may be geared up to identify all potential areas for energy efficiency optimization in every part of the telecom network such that all parts of the telecom networks are addressed to achieve significant reduction in Carbon Emission. Some key aspects related to necessary framework for accurate estimation, setting realistic national targets for carbon emission reduction, automatic online gathering of carbon emission parameters from Infrastructure provider (IP) and telecom equipment based on IoT Framework have been presented for suitable consideration for related policy formulation. The paper summarizes the need for Standardization and policy formulations actions to achieve good progress in making telecom network infrastructure sustainable.
\end{abstract}

Journal of ICT Standardization, Vol. 1, 221-240.

doi:10.13052/jicts2245-800X.12a7

(c) 2013 River Publishers. All rights reserved. 


\section{K. Sirohi}

Keywords: Carbon Emission Estimation \& Reduction, Carbon Foot-printing, TRAI, Traffic Profile, Green Telecom, Telecom Service Provider (TSP), Infrastructure Provider (IP), Renewable Energy Technology (RET).

\section{Introduction}

India, as a globally responsible nation, has accorded high importance and committed to reduce carbon emission from its various sources by a definite percentage in a time-bound manner. The percentage contribution of the Telecom Network with respect to other carbon emitting sectors is insignificant currently, but considering the expected growth in the telecom networks especially in rural area with poor grid power situation and with the increased data services, its potential for a significant rise is very high. The national leadership (regulatory and telecom service providers) is determined to achieve lowest level of carbon emission by leveraging all opportunities ie, developing new and adopting energy efficient (green) telecom technology in Indian Network, optimizing all operational aspects leading to a minimum energy consumption and by adopting Green Energy sources to run the telecom infrastructure. Timely initiative of Indian Telecom Regulatory Authority (TRAI) of releasing its "Recommendations on Green Telecom" in consolidating entire telecom sector stakeholders opinion and providing clear direction for achieving green telecom objectives and later transforming them into mandatory operational requirements to Telecom Service Providers (TSP) is a strong step in the direction.

Currently, a very large proportion of the total telecom networks carbon is emitted by Diesel operated Generators to feed power to mobile network Base Station Sites. Passive infrastructure of these base station sites that includes power, tower physical space and security/operating personals of the telecom networks is being managed by non-Telecom Service Providers (TSP) business entities called Infrastructure Providers (IP). IP offers these services on shared basis for many TSPs as the tenants of their facility.

According to the prevailing Green Telecom Regulations, TSPs have started working out total Carbon Emission Estimates (CEE) of their respective Telecom Network, started submitting to DoT and TRAI on half yearly basis where this data is expected to be analyzed for to accuracy verification and to assess the expected mandatory reduction in CEE on year by year basis.

TSPs are dependent on Infrastructure Providers (IP) for providing major accurate data required for calculating the carbon emission for their base-station sites. The data being providing by Infrastructure Provider (IP) is normally questioned for its accuracy. The problem is further aggravated when the 
CE iscalculated based on the formula recommended by TRAI that accounts Carbon emission based upon the Maximum power generating capacity of the Diesel Power Generator used to power large number of Basestation sites, not on the basis of the power consumption of the Telecom Equipment (BTS with is associated cooling system). Boththe factors collectively contribute to a significantly higher estimate of carbon Emission than actual. The extent of error is estimated to be of the order of the reduction targets set for achieving during the next few years. The current situation where Diesel Power Generators are considered to be dirty source of energy for meeting the power consumption requirements to the Mobile Radio Basestation is accorded the highest importance. The entire focus of the entire Telecom Sector in India is only towards replacing Diesel Power Generation sites by Renewable Energy Technology (RET). All the techno-commercial feasibility issues related to Diesel Generator substitution with RETs are being treated as if it is the only cause for poor carbon emission state of Indian Telecom. This perception has created insensitivity towards achieving Energy Efficiency in other parts of the segments of the Telecom Networks. Adequate timely attention to achieve energy efficiency in the telecom network with evolution of necessary Standards for measurements and metrics of energy efficiency, development of energy efficient technology building blocks, telecom products and the operating methods must be treated with equal importance.

Additionally, there is an urgent need,in the country,for necessary framework of the consolidated data used for estimation of Carbon Emission from all the TSPs as national Telecom Carbon Emission Platform. The platform is to be utilized by the Government and the Industry to draw useful intelligence as required to formulate a realistic national plan for Carbon Emission Estimation $\&$ Reduction (CEER) and also provide the firm direction to Telecom Service Providers, Telecom Equipment manufacturers and the Telecom Technology innovators for achieving national goals of higher energy efficiency in Indian Telecom and realize a sustainable telecom infrastructure in India. The same can be achieved by evolving and adoptinga holistic approach at a national level so that all the parts of the telecom networks be subjected to separate energy efficiency review and optimization by adopting currently available energy efficient Telecom Equipments, by motivating and supporting development of innovative energy efficiency technology of Telecom equipment, optimizing operating methods for achieving energy efficiency in telecom operation and also by converting polluting to greener energy sources.

This paper discusses current methods, associated issues and proposes some perspective that would be necessary for evolving necessary holistic plan for 


\section{K. Sirohi}

Carbon Emission Estimation and Reduction for India's Telecom services. This approach will set a technically sound ground for setting up reasonable expectations and deterministic approach of achieving the set national targets for telecom carbon emission. Detailed and holistic approach as proposed in the paper helps in identifying all potential problematic areas to draw equal attention from Government and Industry for its resolution. The expected outcome include the identification of all areas of energy consumption suboptimality, definition of required policy/methods for addressing them leading to achieve set objectives and to establish India's global leadership in the field of telecom network carbon emission reduction.

\section{Parts of Telecom Networks and Their Respective Carbon Emission Estimates}

Referring TRAI Recommendation [1], one of the possible classifications of entire Telecom Networks into various network segments has been presented in the following table (Table 1):

The average percentage proportion of the power consumption and hence estimated carbon emission from these network segments have been presented in Figure 1 above.Closer view of the Figure 1 suggests that the major most portion of the carbon emission is contributed by the Mobile network. The base stations alone contribute to $59 \%$ of the total carbon emission of the entire mobile network. Remaining $41 \%$ carbon emission of the entire mobile network is being contributed by rest of the network. The carbon emission estimates of various segments of the telecom network sets the priority for addressing carbon emission problem.

\section{Problem Defintion of Carbon Emission Estimation (CEE)}

The carbon emissions estimation depends on two factors i.e. the power consumption of the telecom equipment (along with its mandatory cooling system requirements) and the carbon emission factor associated with the power source being used for powering the telecom equipment.

The first part of the problem is the right measurement of the power consumption of any telecom equipment deployed in the live network that variessignificantly over the time cycle of 24 hours. There must be a appropriate method to measure accurate power consumption that is required for the 
Carbon Emission Estimation \& Reduction in Indian Telecom Operations 225

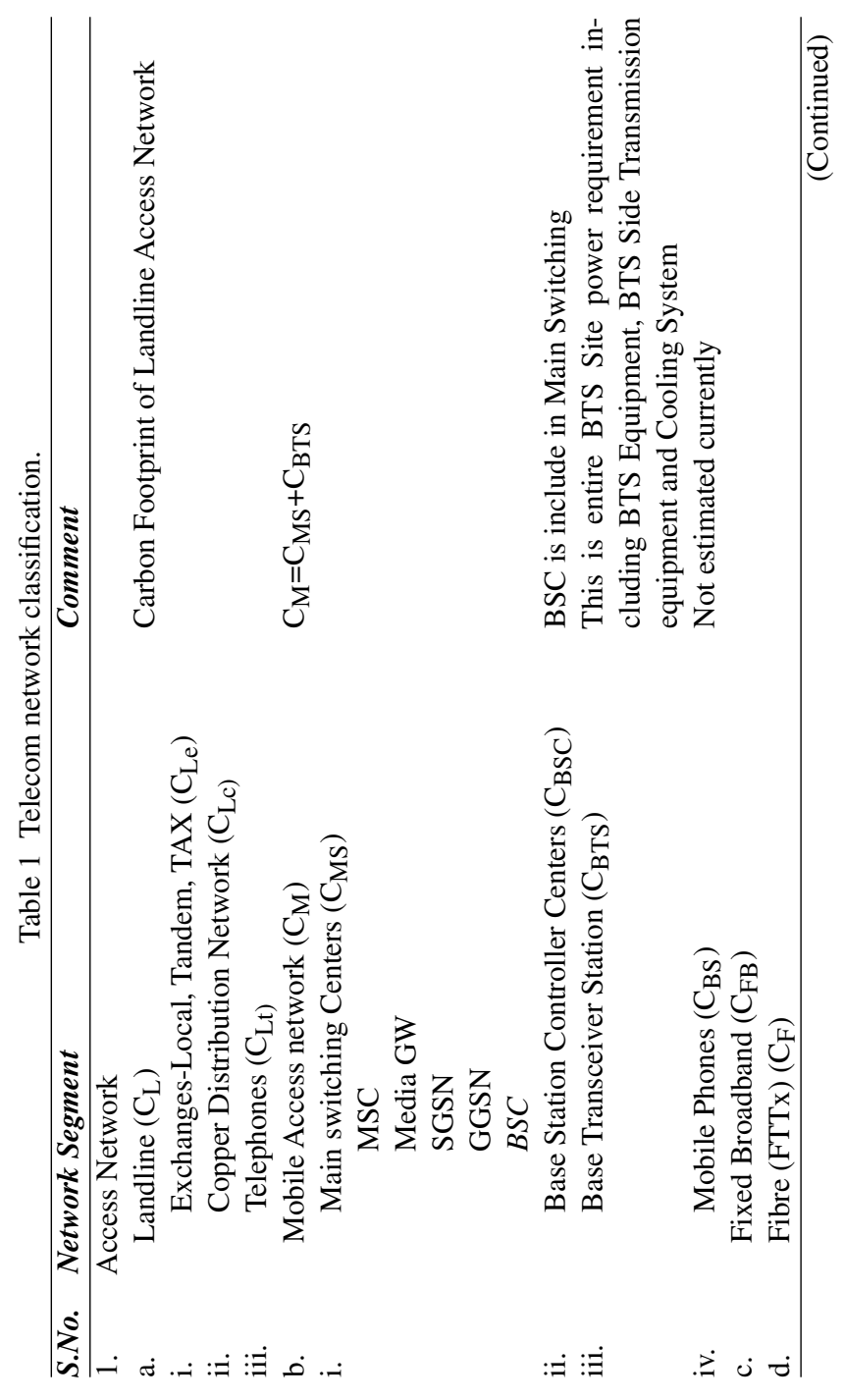




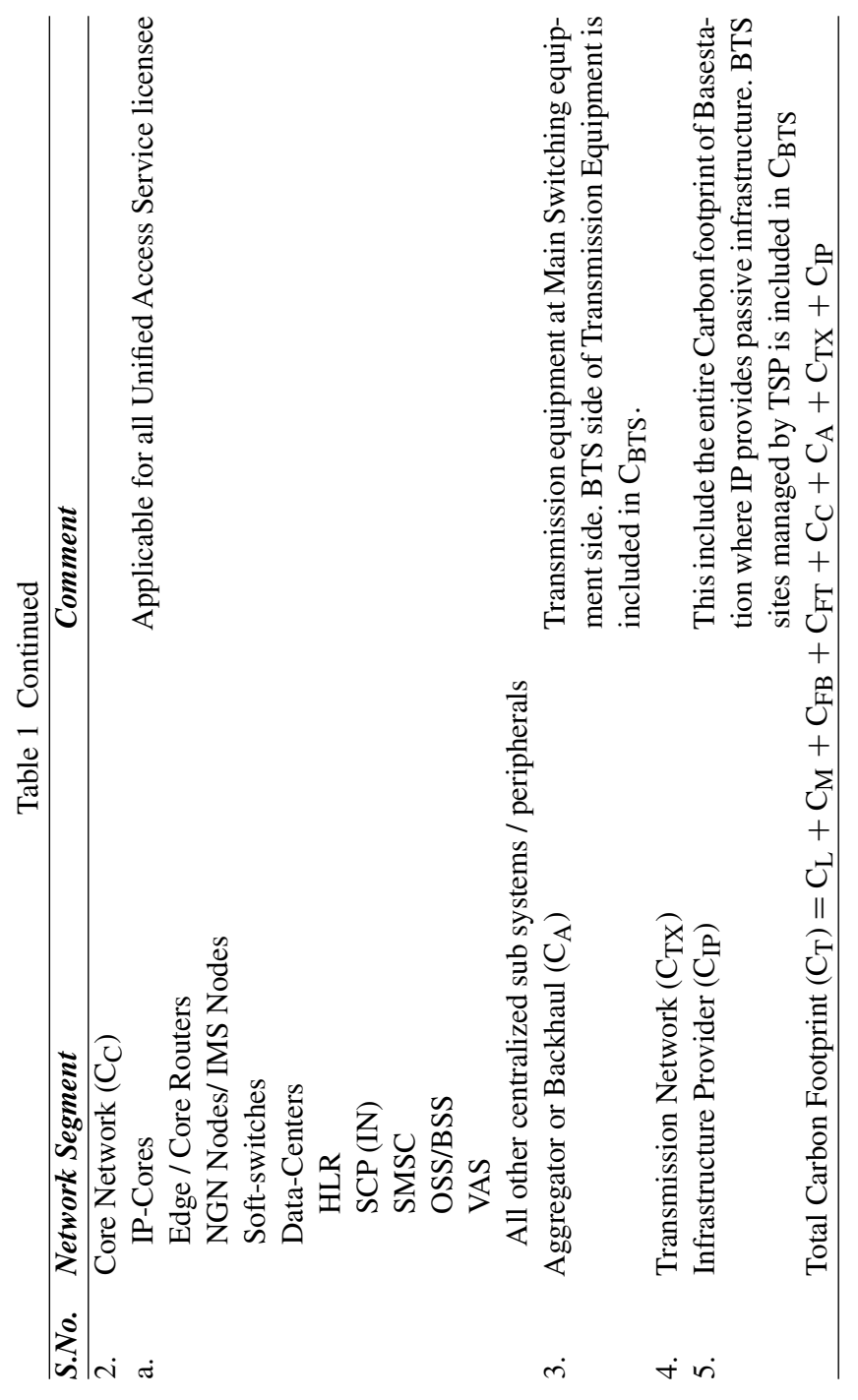




\section{Power Consumption}

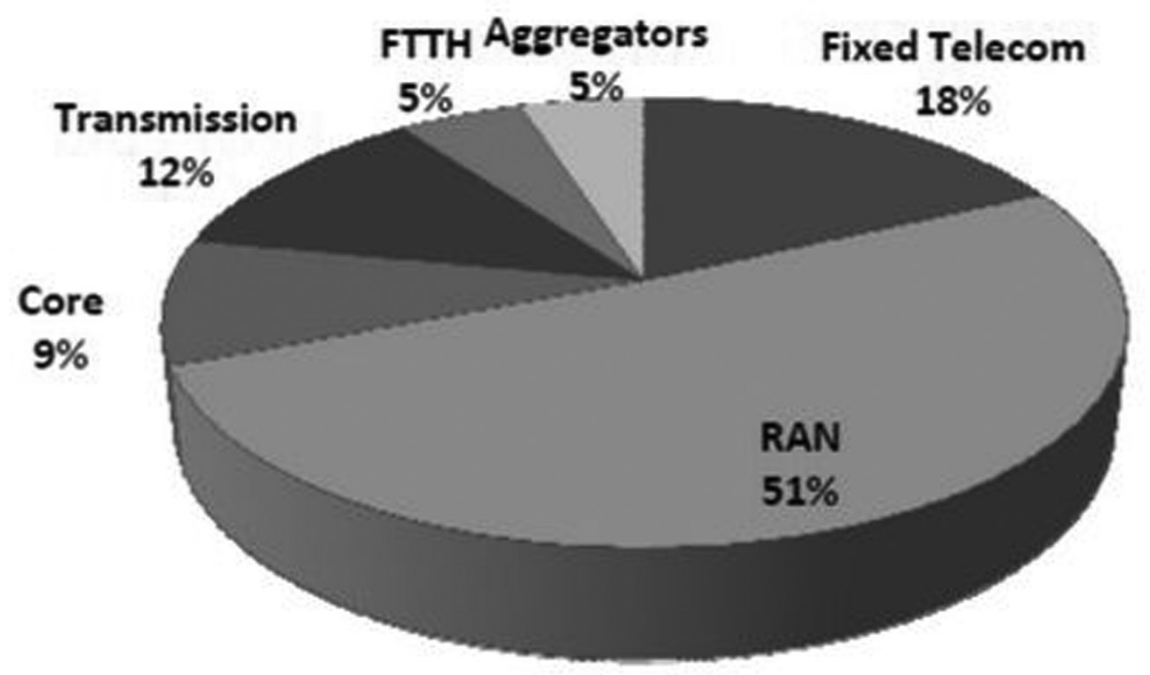

Figure 1 Power consumption breakup.

estimation of Carbon Emission. This problem will be dealt in more details in later section.

The second part of the problem i.e. the carbon emission association with the power sources used to power the telecom equipment power need. This factor is particularly prevailing in the developing world where the Grid power is not sufficient to run the telecom infrastructure. Availability and the quality of Grid power in various parts of the country varies significantly. Particularly in the rural areas, where grid power availability is extremely poor, the telecom services majorly depends upon the power generated by burning Diesel as fuel in large number of power generators deployed across the country.

In general, any Telecom Equipment's power consumption requirement $\mathrm{P}$ can be considered as being met by various power sources i.e. Grid, Diesel or any Renewable Energy Technology (RET) like Solar. For each type of power source there is an associated Carbon Emission Factor i.e. $\mathrm{CF}_{\mathrm{g}}$ for Grid Power, $\mathrm{CF}_{\mathrm{d}}$ for Diesel and $\mathrm{CF}_{\mathrm{r}}$ for Renewable Energy Source. The problem definition is presented in Figure 2.

If the power consumption need of the telecom equipment is met for $T_{g}$ Duration from Grid, $T_{d}$ from Diesel and $T_{r}$ from Renewable Power Source 


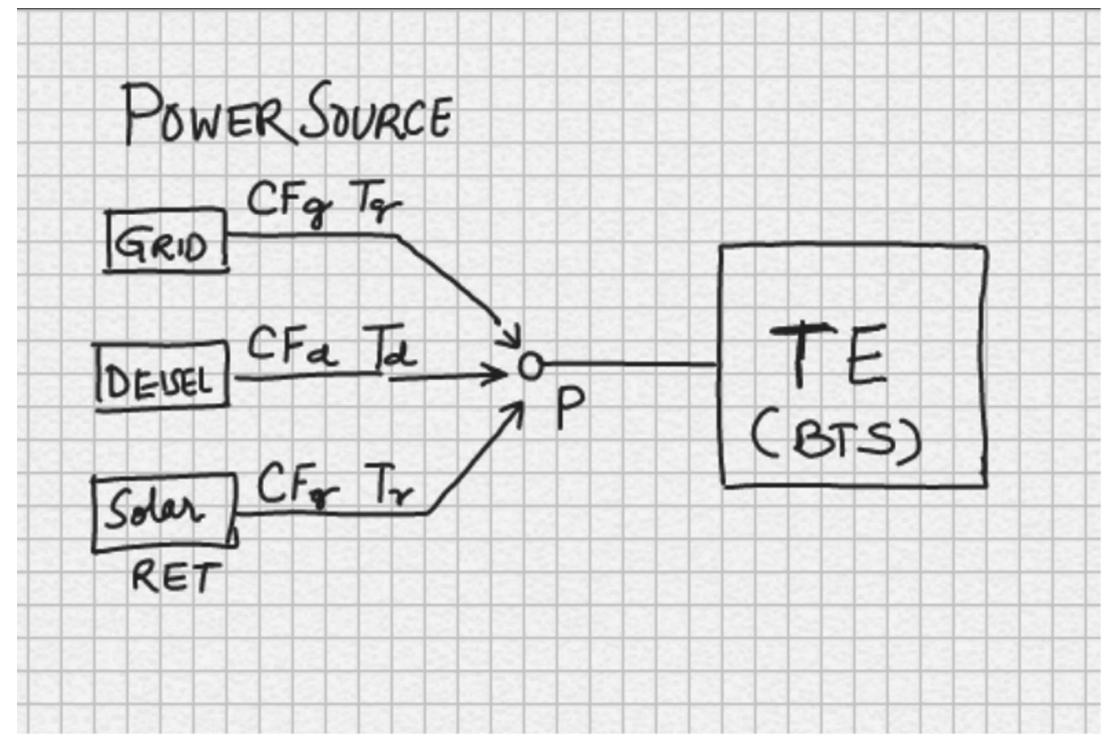

Figure 2 Carbon emission problem definition.

during a day cycle (24Hrs), the carbon emission of the telecom equipment during that day can be viewed as:

$$
\text { Carbon Emission } \mathrm{CE}=\mathrm{P} \times \mathrm{CF}_{\mathrm{g}} \times \mathrm{T}_{\mathrm{g}}+\mathrm{P} \times \mathrm{CF}_{\mathrm{d}} \times \mathrm{T}_{\mathrm{d}}+\mathrm{P} \times \mathrm{CF}_{\mathrm{r}} \times \mathrm{T}_{\mathrm{r}}
$$

Considering the significant variation in different Carbon Emission Factor (CF) and Duration (T) for a given telecom equipment, the above formula motivates one to:

i. Reduce the power consumption of the telecom equipment itself, and

ii. Reduce the duration of the power source which has high Carbon emission Factor $(\mathrm{CF})$.

First part of the problem is to reduce the Power consumption of the telecom equipment is the mandate to Technology Researchers and for the innovators in Telecom technology and Equipment design. The size alone of the total telecom infrastructure requirement in India necessitates high focus to be accorded by policy makers and the telecom technology/product developer and innovators.

Second part of the problem is to reduce the duration of the CarbonExpensive power source (like Diesel burning) or eliminate it altogether wherever technologically and economically feasible. 
Both the problems needs different set of policies, investments, and expertise to solve. Therefore, both the problems need timely, separate and adequate attention from the concerned people or authorities, so that the carbon emission problem can be rightly understood and addressed completely. Attempt to resolve just one of the problems, as it appears to be the current case in India, will lead to achieve limited results. This paper suggests necessary timely action for the first part of the problem.

\section{Dynamic Power Consumption Based Accurate Estimation of Carbon Emission}

Another aspect for considerations is the true nature of the power consumption for any telecom equipment. Considering the 24 hours usage profile of any telecom equipment, the power consumption is never static. It changes significantly depending upon the traffic that the telecom equipment handles at any point of time. The traffic experienced by the telecom equipment varies with the time of the day based on various traffic generating characteristics

It is important to note that the average dynamic power consumption of any telecom equipment is significantly lower than the static maximum power consumption. The Carbon Emission Estimates as currently done based on the maximum power consumption of the telecom equipment, are much higher than the actual estimates. This error in carbon-footprint estimates, alone, may come out to be more than the carbon emission reduction targets that has been set to be achieved during the next five years. Therefore, it is necessary to establish the total CEE baseline (as decided to be 2011 year) for any TSP accurately and should be based on dynamic power consumption.

The important fact of estimating carbon emission based on dynamic power consumption was well recognized by Telecom Standards Development Organizations like ETSI[4][5], ATIS[6], ITU-T \& GISF[2][3]I. All graduated by evolving their energy consumption measurement methods based on the Dynamic Power consumption. The external organizations ETSI, for example, evolved a high level framework for developing the energy efficient measurement standards based on dynamic power consumption for the Mobile Networks based on $3 G \&$ LTE wireless technologies. They did not find it relevant to do the same for the GSM network considering the limited life of the GSM network in Europe. However considering the high relevance in India, GISFI decided and achieved progressed to develop the same for GSM network. 
The Energy Efficiency Standards as developed by the Global Standards development organization are high level frameworks with necessary guideline to be adopted.This necessitates the detailed exercise to be carried out by the Telecom Service Providers themselves to evolve necessary parameters based on the experienced traffic in their respective networks. Additionally, the traffic models that are considered in developing such frameworks by global standards development organization significantly varies from the one experienced in India and particularly the mobile networks deployed in Rural India. India's high population density and the demography and the extent of the available telecom service in Rural areas have created absolutely new traffic models that need to be studied by the local organizations and the existing gaps in the current global standards must be filled. GISFI is making good progress in its chosen mandate of such study and developing required national standards. Telecom Engineering Center (TEC) of Government of India, in its currently ongoing "Green Passport" definition exercise has established such India Specific needs that must be filled by Indian initiative.

This exercise will include any active traffic analysis to define the relevant (say k different types) Traffic classes (TC), prevalent duration $\left(\mathbf{T}_{\mathrm{k}}\right)$ of each traffic class and the measurement of dynamic power consumption $\mathbf{P}_{\mathrm{k}}$ for each traffic class for all the network elements deployed in the telecom network. The concepts is summarized in Figure 3.

In this scenario, the total power consumption of the telecom equipment during the day ( $24 \mathrm{hrs})$ can be calculated as:

$$
\mathrm{P}_{\text {dynamic }}=\Sigma \mathrm{P}_{\mathrm{k}} \times \mathrm{T}_{\mathrm{k}}
$$

for all $\mathrm{k}$ traffic Classes

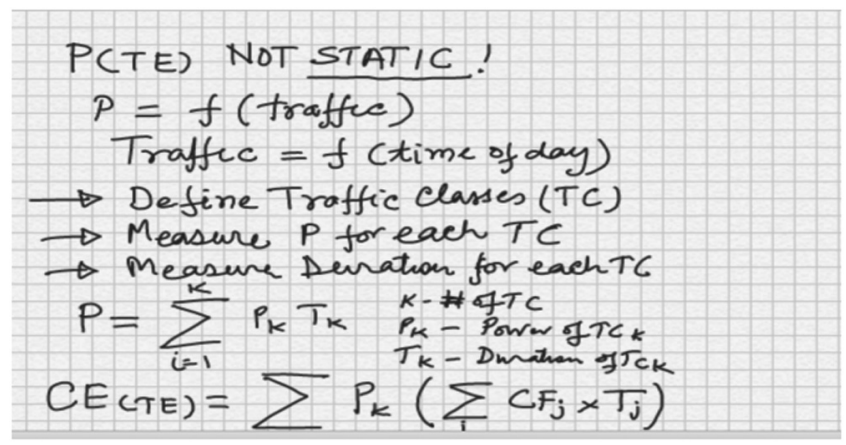

Figure 3 Carbon emission based on dynamic power consumption. 
And therefore Carbon Emission for the telecom equipment can be calculated as:

$$
\mathrm{CE}_{\text {dynamic }}=\Sigma \mathrm{P}_{\mathrm{k}} \times\left(\Sigma \mathrm{CF}_{\mathrm{j}} \times \mathrm{T}_{\mathrm{j}}\right)
$$

for all ' $\mathrm{j}$ ' types of different power source with their different applicable Power Emission Factor.

\section{Benefits of Dynamic Power Consumption Based CEE}

Implementation of dynamic power consumption based Carbon Emission Estimation methods has potential to lead to following significant advantages:

i. CEE is accurate and significantly less than the current estimates. This will improve Indian telecom benchmark of carbon emission on per subscriber basis in comparison of international figures.

ii. The traffic analysis as required to carry out this dynamic power consumption assessment, will lead to identify various existing potential cases of sub-optimal energy utilization.

iii. Identification of prevailed such cases of sub-optimal energy efficiency will motivate Telecom Service provider's operation experts to align telecom equipment design experts to evolve necessary design refinements to eliminate the sub-optimality. This will lead to a significant potential CEE reduction and hence significant power saving i.e. the OPEX reduction.

\section{Current Methods for CEE and the Associated Issues}

As discussed in the earlier sections (3), the carbon emission of a telecom equipment which power consumption needs are met by multiple power sources with its associated carbon emission factor and the duration of each power sources as application is best represented as:

$$
\text { Carbon Emission } \mathrm{CE}=\mathrm{P} \times \mathrm{CF}_{\mathrm{g}} \times \mathrm{T}_{\mathrm{g}}+\mathrm{P} \times \mathrm{CF}_{\mathrm{d}} \times \mathrm{T}_{\mathrm{d}}+\mathrm{P} \times \mathrm{CF}_{\mathrm{r}} \times \mathrm{T}_{\mathrm{r}}
$$

One this generic situation is reduced to a case when the power needs are met by two sources i.e. Grid and Diesel, the above formula should get reduced as:

$$
\text { Carbon Emission } \mathrm{CE}=\mathrm{P} \times \mathrm{CF}_{\mathrm{g}} \times \mathrm{T}_{\mathrm{g}}+\mathrm{P} \times \mathrm{CF}_{\mathrm{d}} \times \mathrm{T}_{\mathrm{d}}
$$

According to the TRAI recommendations, the above formula is applicable even for the cases when the power needs are met by power source based on 


\section{K. Sirohi}

Renewable Energy Technology (RET), because the carbon emission factor due to RET based power sources are considered as Zero and these power sources are considered as perfect Green Energy Sources. Additionally, TRAI has not considered the carbon emission for the duration when the Telecom equipment is run from battery and the battery is charged by Non-Green Power.

Significant concerns is raised by the Industry on the formula that has been recommended by TRAI for calculating Carbon Emission when the Telecom Equipment power requirement is met by Grid as well as alternate power source based on Diesel Generator. TRAI's recommendedformula can be viewed as:

$$
\begin{gathered}
\text { Carbon Emission CE (TRAI) } \\
=\mathrm{P} \times \mathrm{CF}_{\mathrm{g}} \times \mathrm{T}_{\mathrm{g}}+\text { DG Capacity } \times \mathrm{CF}_{\mathrm{d}} \times \mathrm{T}_{\mathrm{d}}
\end{gathered}
$$

According to the above formula, there are two parts of the carbon emission. The first part is when the Telecom Equipment power requirement is met by the grid power and the part of the carbon emission depends on the power consumption requirement of the telecom equipment. It is to be noted that the power consumption requirement includes the Telecom equipment power consumption as well as the power required for the equipment mandated cooling system. The second part corresponds to the duration when the Telecom equipment power needs are met by Diesel Generator (DG). In this part, the power consumption requirement of the Telecom Equipment becomes immaterial and is substituted by the Power Generation capacity of the DG. The Power Generating Capacity of the DG is always higher that the power requirement of the telecom equipment. The simple reasons for putting up higher capacity DG are two. The power requirement of the telecom equipment may increase gradually in coming years due to higher demand of the traffic and there is an efficiency loss of the DG, due to aging or operational issues.

When TRAI expects TSP to calculate the Carbon Emission as per their recommended formula, one should notice that the power consumption requirement of the telecom equipment has become absolutely immaterial. This phenomenon when clubbed with large number of rural sites where Diesel consumption is high, becomes so prominent that the energy efficiency aspect of the telecom networks practically vanishes.

The DG capacity deployed in the field is not just slightly higher to cater to the factor mentioned above, but it is practically much higher. Typical DG capacity for non-shared site is $15 \mathrm{KVA}$ and for shared site, it is minimum $25 \mathrm{KVA}$, while the power consumption requirement is typically $3 \mathrm{KVA}$ for non shared, 10KVA for shared sites. This is one major cause for escalated estimation of Carbon Emission in Indian Telecom Service provisioning. Situation is 


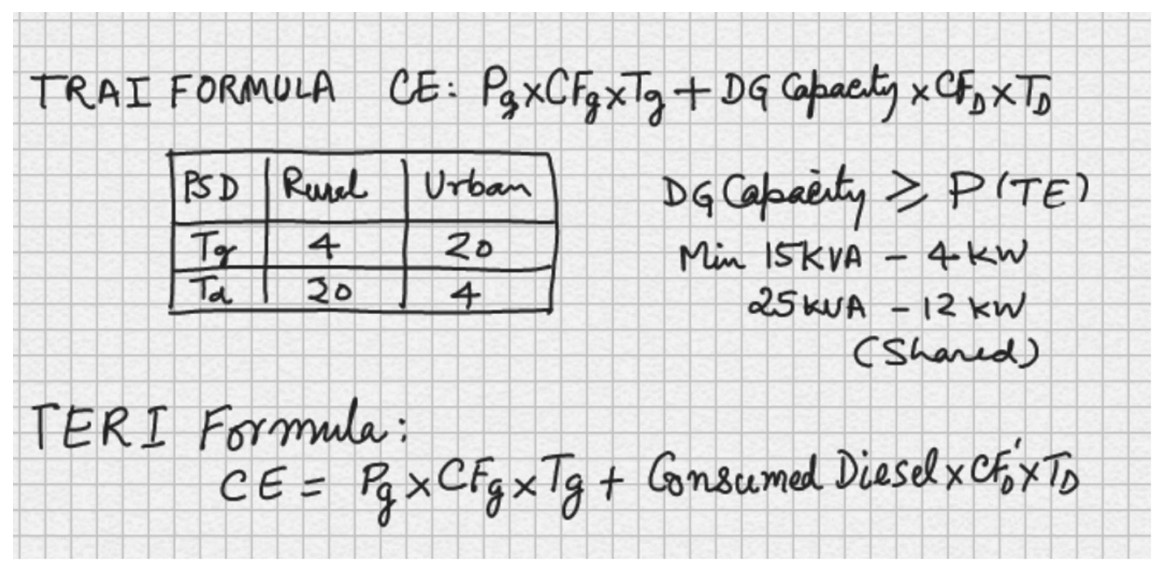

Figure 4 Diesel dominating access carbon emission estimates.

described in Figure 4 above. The access power generator at the Basestation sites by the Infrastructure providers $(I P)$ is the increased revenue to the IP, increased (wasteful) operating expense to TSPs which are being billed for the access power and unreasonably high carbon emission from Indian telecom networks degrading environment.TSPs are sufferer of the increasing power expense and unfortunately have no control to reduce it.

The problem becomes more critical when the typical duration for active DG operation become as high as $20 \mathrm{Hrs}$ (out of total $24 \mathrm{Hrs}$ in a day) in remote rural areas.

The accumulated effect of these two factors has contributed to the TRAI's alarming calculation of $21 \mathrm{~kg}$ of carbon emission per subscriber in India against the international figure of $8 \mathrm{~kg} / \mathrm{per}$ subscriber.

With these factors, the entire Carbon Emission Estimation and Reduction(CEER) exercise in India is reduced to the single agenda of converting Diesel power source to Renewable Energy Technology based power sources. This exercise requires huge investments and TSP are finding it extremely difficult to justify the investment if it is to be executed from their internal accruals. More Governmental support is demanded, if the TSPs are expected to meet the current Green telecom mandatory regulations. The extent of the DG-RET power source conversion problem, especially with current deployment of energy inefficient mobile network base-station telecom equipment is assessed so huge that there is no practical solution visible in near future.

The problem will take different shape and size and possibly get changed from the currently 'unviable' to 'viable' category, if the DG-RET power source 


\section{K. Sirohi}

conversion problem is judiciously clubbed with adoption of higher energy efficient base-station equipment with suitable deployment architectures, wherever possible. This will reduce the solarpanels requirement for powering the energy efficient base-station sites with a great factor.

Telecom industry often demands TRAI to atleast change TRAI formula to TERI formula where the DG capacity is replaced by the actual Diesel consumption. TERI formula also does not address the key limitation of TRAI formula and is equally sub-optimal; however it shows 8-10\% less carbon emission estimation.

\section{Concept Proposal for Treating IP'S Access Power Generation}

TRAI's view of accounting entire carbon emission due to Diesel generator at the Basestation site sounds logical. The logic is based on the fact that the sole purpose to run the diesel generator at Basestation site is only to provide power to the BTS equipment. Otherwise, there was no other reason for running the DG at Basestation site location leading to any carbon emission.

However, it is meaningful to have comprehensive view of Carbon Emission Estimation problem definition. It calls for consideration of Infrastructure Provider (IP) as a business entity that can play increased role, accountability and increased business opportunity in the overall exercise of Carbon Emission Estimation and Reduction for TSPs. The IP can be visualized a responsible business entity that provide Power from multiple power sources like Grid, Diesel or RET (Solar) and meeting the need of the multiple TSPs as per the actual need of the Telecom Equipment.

In the process, IP happens to generate some access power that has a potential to be utilized for non-telecom purposes. Irrespective of the proper utilization of the access non-telecom power, it is meaningful to account this access power as non-telecom power generated by IP. Therefore total carbon emission of an IP site (shared among TSPs) can be accounted as two factors, one that is due to TSP actual power consumption requirement and another due to access non-telecom power. The same concept has been summarized in Figure 5.

Carbon Emission of an IP (Infrastructure Provider) as defined in TRAI recommendation may suitably be changed as

$$
\mathrm{CE}_{\mathrm{IP}}=\mathrm{CE}_{\mathrm{NON}-\mathrm{TELECOM}}+\Sigma \mathrm{CE}\left(\mathrm{TSP}_{\mathrm{i}}\right) \text { for all sharing TSPs }
$$




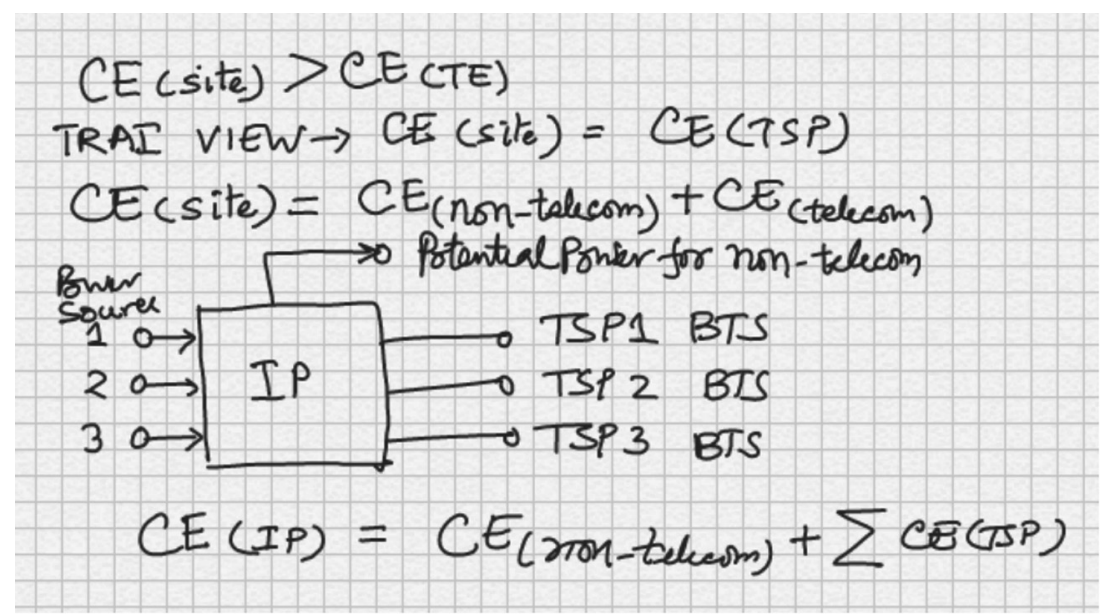

Figure 5 Non-telecom carbon emission.

Carbon Emission for all sharing TSP must be based on the actual power consumption ratio. Till the time the access power at IP remain unutilized, the same Carbon Emission for the non-telecom could also be distributed to TSP in the ratio of their power loads, but should remain separately accounted.

Similarly the total carbon emission for any TSP should include a separate entity as $\mathrm{CE}_{\mathrm{NON}}$-TELECOM that lead the currently specified TRAI formula for total Carbon Emission calculation for Telecom Service Provider as:

$$
\mathrm{C}_{\mathrm{T}}=\mathrm{C}_{\mathrm{L}}+\mathrm{C}_{\mathrm{M}}+\mathrm{C}_{\mathrm{FB}}+\mathrm{C}_{\mathrm{FT}}+\mathrm{C}_{\mathrm{C}}+\mathrm{C}_{\mathrm{A}}+\mathrm{C}_{\mathrm{TX}}+\mathrm{C}_{\mathrm{IP}}
$$

should be suitable changed as:

$\mathrm{C}_{\mathrm{T}}=\mathrm{C}_{\mathrm{L}}+\mathrm{C}_{\mathrm{M}}+\mathrm{C}_{\mathrm{FB}}+\mathrm{C}_{\mathrm{FT}}+C_{\mathrm{C}}+\mathrm{C}_{\mathrm{A}}+\mathrm{C}_{\mathrm{TX}}+\mathrm{C}_{\mathrm{IP}-\text { NonTelecom }}+\mathrm{C}_{\mathrm{IP}-\mathrm{TSP}}$

Magnitude of National consolidation of $\mathrm{C}_{\mathrm{IP}-\text { NonTelecom }}$ will decide what importance must be accorded by the country and how the progress on this access power utilization will be tracked.

\section{Decomposed Problem Sets the Specific Focus and Clear Responsibility for Carbon Emission Reduction}

This approach of decomposing the Carbon Emission problem with such holistic details creates opportunity to identify various aspects of the problems and sets the separate specific focus to address them. These specific aspects are 


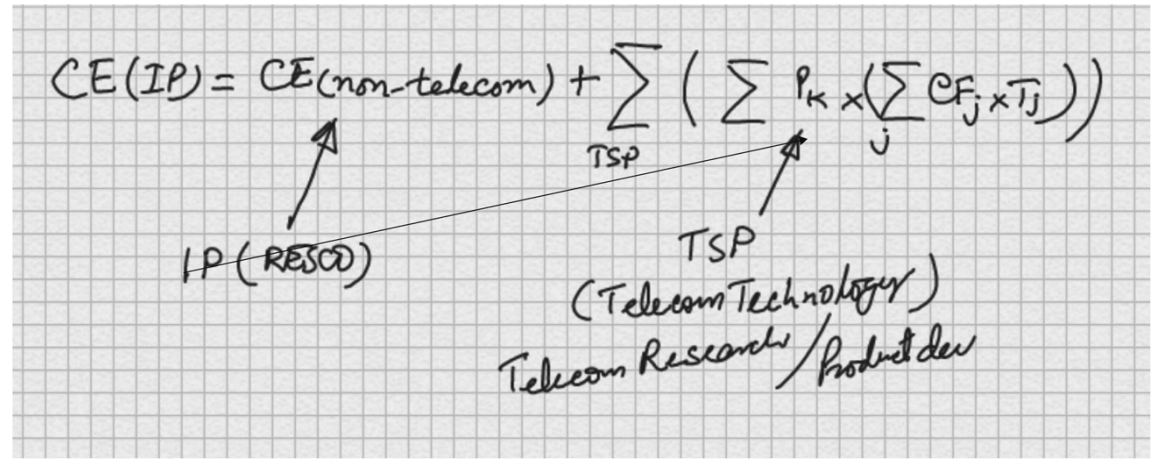

Figure 6 Estimation details sets responsibility to fix it.

related to the all the parts of the networks that forces to evolve and adopt all possible methods and procedure to reduce power consumption. It creates defined need for innovation in energy efficiency for future and of current telecom equipments. This will also fixed targets to utilize non-telecom power for alternate purposes and accounting the associated carbon emission as out of TSP budget. This will make RESCO model practical and in demand. The concerned policy making and business related actions would achieve speed. The Carbon emission breakup and the separate responsibility to address the problem is summarized in Figure 6.

By doing so, it also sets the clear responsibility of TSP to motivate development and adoption of innovations carried out in energy efficiency and associated methods to reduce the power consumption and hence the saving on OPEX.

A meaningful comprehensive frame work for the Carbon Emission Estimation and Reduction will prove helpful to evolve necessary policy changes to streamline the sector and help achieving the set target of carbon emission reduction.

With such approach and details of operation and understanding, it would be beneficial to set the Carbon emission reduction targets for each segment of the network that constitute the total carbon emission of a TSP as per the TRAI classification (section 2) and the recommended formula mentioned in previous sections as:

$\mathrm{C}_{\mathrm{T}}=\mathrm{C}_{\mathrm{L}}+\mathrm{C}_{\mathrm{M}}+\mathrm{C}_{\mathrm{FB}}+\mathrm{C}_{\mathrm{FT}}+\mathrm{C}_{\mathrm{C}}+\mathrm{C}_{\mathrm{A}}+\mathrm{C}_{\mathrm{TX}}+\mathrm{C}_{\mathrm{IP}-\text { NonTelecom }}+\mathrm{C}_{\mathrm{IP}-\mathrm{TSP}}$ 


\section{IOT Based System for Automatic Collection of Carbon Emission Parameters}

The systems for automatic gathering the parameters required for estimating carbon emission would also be required to achieve the full objective of such a comprehensive solution for carbon emission estimation and reduction for establishing global leadership in this field. One of significant standardization delivery from GISFI's Technical Working Group on "Internet of Things (IoT)" as Application domain independent Generic Framework of IoT Based solutions is very appropriate candidate to be adopted for developing such system for Telecom Carbon Emission in India.

\section{Conclusion}

India has made a very good beginning towards achieving the Green Telecom objectives. Current regulatory definitions need refinements in terms of estimating the accurate Carbon emission from Telecom Network Equipments and setting up the reasonable and realistic targets of reduction in carbon emission.

The green telecom goal setting and the obligatory compliance will require necessary policy reforms that must be based on the sound study outcome carried out by Indian standardization organization with active participation from Telecom Service Providers, Telecom equipment providers, Technology Research \& Development Organization and Government.

Some of the key Standardization and Policy formulation objectives are:

Evolution and adoption of the accurate carbon emission measurement estimation suitable for Indian telecom network.

Setup a national framework of information that contains the entire information related to carbon emission estimation from all the telecom service providers and Infrastructure providers. The common framework must be utilized for consolidating nationwide carbon emission estimates and study the necessary trend. This framework must relieve TSP to provide large reports as prescribed today. Regulator should also be able to draw necessary interpretation with regard to the verification of carbon emission data, estimation reports to check regulatory compliances and setting up the realistic and reasonable future goals.

Establishing a system for automatic information collection from the source of the information by building necessary technical mechanisms utilizing the recent advances in technology and their technical standards. The source of the information in this case is Infrastructure provider (IP) for providing 
Switch-On/Off timing for various types of power sources and the consumed power. The source also includes inbuilt capability of each telecom equipment to assess and report the dynamic power consumption based on experienced traffic.

Adequate and immediate focus on achieving energy efficiency in the telecom network by following necessary Standards for measurements and metrics of energy efficiency, development of energy efficient technology building blocks, telecom products based on such building blocks and their adoption in the network under a national framework.

Access power generation at the Basestation sites is one major cause for escalated estimation of Carbon Emission in Indian Telecom Service provisioning that should be treated as separate problem to address. There should be a nationwide consolidation of the unutilized access power generated by IP for meeting the TSP requirement and a suitable policy should be formed for its utilization.

In order to provide adequate focus on the overall carbon emission reduction exercise, it would be necessary to set separate target of the carbon emission reduction for all the network segments separately.

\section{References}

[1] Telecom Regulatory Authority of India-Recommendations on Approach towards Green Telecommunications, 12 Apr, 2011

[2] GISFI TR GICT.105 V1.1.0 (2012-12): Metrics and Measurement Methods for Energy Efficiency

[3] GISFI TS GICT.101 V1.0.0(2013-02) Metrics and Measurement Methods for Energy Efficiency: Classification of Telecommunication Equipments; (Release 1)

[4] ETSI TR 102530 V1.1.1 (2008-06) Environmental Engineering (EE) The reduction of energy consumption in telecommunications equipment and related infrastructure

[5] ETSI TR 102532 V1.1.1 (2008-06) Environmental Engineering (EE) The use of alternative energy solutions in telecommunications installations

[6] ATIS-0600015.2009: Energy Efficiency For Telecommunication Equipment: Methodology For Measurement and Reporting - General Requirements (Baseline Document) 


\section{Biography}

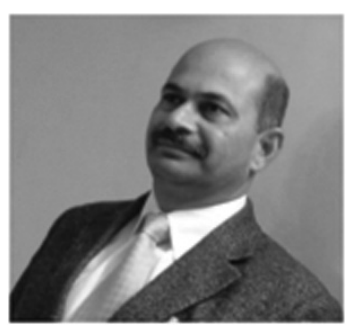

Krishna Sirohi has 25 years of experience from technology development leadership within both the telecom field and the defense sector. He is currently heading Impact Innovation in Technology \& Business (i2TB) a technology incubation enabler unit of Samridhi Projects Private Limited (SPPL). i2TB is currently associated with few Technology Startup initiatives in their early or growth stages as well as with established organizations establishing their new technology businesses. He also heads Standards Committee of GISFI, the Global ICT Standardization Forum of India. GISFI is aligned with national policies and program in the field of Telecom, IT \& Service based on emerging ICT infrastructure. He has been founding CTO of VNL, India's first initiative in private sector to develop sustainable rural telecommunication infrastructure using wireless technology. Prior to VNL he had served in Government's three major Indian R\&D organizations in the field of Telecom and Defense Electronics. These organizations are CDOT, Bharat Electronics and Indian Telephone Industry.

Krishna has a Masters degree in Engineering (4 years Integrated course) from the Indian Institute of Science at Bangalore in year 1988 and BSC $(H)$ in Physics from Delhi University.

He has been associated with technology development program of national importance. These programs includes India's first Large Capacity digital Switch design at ITI, India's first indigenous Command-ControlCommunication-Intelligence (C3I) System for Indian Navy's Warfare Ships at BEL, India' first Mobile Network technology development program at CDOT and most innovative rural wireless solution at VNL.

He has represented in various international organizations and forums and contributed several internal forums and policy making exercises for domestic technology development programs.

He has been Vice-Chair of Special Interest Group (SSG) on "Beyond 3G Systems" of ITU-T and has leaded the standardization of Fixed and Mobile network convergence.

Email: president@i2tb.in, krishna.sirohi@gmail.com (alternate) Phone: +919899488800 
